\title{
An Assessment of Ghanaian Colleges of Education Readiness for e- Learning Given COVID-19 Pandemic
}

\author{
David Otoo-Arthur ${ }^{1}$, Emmanuel Kabutey Koranteng ${ }^{2}$, Joseph Kingsley Amoah ${ }^{3}$ \\ University of Education, Winneba ${ }^{1}$, Presbyterian Women's College of Education, Aburi ${ }^{2,3}$ \\ Ghana
}

\begin{abstract}
This paper investigates how Ghanaian colleges of education students are responding to the rapidly changing educational structures, instruction and pedagogy given COVID-19 pandemic. Particularly, we focus on the readiness of students for online learning, and the level of support tutors and administrators are offering to ensure a smooth transition. We present the critical hurdles that need to be addressed for successful adoption and implementation of e-learning programmes. The study adopts a mixed-method approach to examine students' involvement and perspectives in online teaching and learning in higher education given COVID-19 pandemic. The nature of this study is descriptive, explanatory and evaluative. Primary data were collected through an online survey conducted from March 1 to August 30, 2020, with a total of 506 respondents from all the forty-six (46) public colleges of education in Ghana. Our findings show increased adoption of e-learning as a result of the pandemic. However, access, lack of clear policies on acceptable use of ICT, poor technological infrastructure, financial constraints, lack of e-learning knowledge, inadequate support and training have led to a slow-pace in adapting to the new norm.
\end{abstract}

Keywords: COVID-19, e-Learning, Pedagogy, Higher Educational Institutions, TF-IDF

\section{Introduction}

Teaching and learning undoubtedly have been receiving enough disruptions lately from the widespread of COVID-19 of which colleges of education (CoEs) in Ghana are no exception. The global spread of COVID-19 has impacted over 91 per cent students nationwide as a result of the temporary closure of schools in many countries [1]. These disruptions have caused phenomenal transformations in the educational landscape, which has mainly been driven by Information Communications and Technologies (ICTs). The adoption and use of these ICTs have not only improved education and learning but added various extensions, substitutions, and blending of new pedagogical approaches and technologies that inject new trends to teaching and learning. However, colleges of education are still at the cradle of adopting and adapting to online learning paradigm in order to stay competitive in the academic space.

The challenges of colleges of education in Ghana engaging in online learning has to do with innovation and implementation, and the need to rapidly adapt to, sustain and to be abreast with the pace technology is evolving and affecting our lives and education in the case of COVID-19. A recent study by Horrigan [1] showed that some users are unable to make use of the internet and mobile devices adequately for key activities like searching for information. This case is not different in the colleges of education, where different users of technology have varying levels of preparedness and usage for using emerging tech tools for teaching and learning. These differences, however, may result in the possibility of uneven adoption and use of technology and could have a dire consequence on users. Adoption of tech tools have been usually characterised by the "haves and have not", digital skills level and trust in technology [2]. The colleges of education, therefore, need to be ready to readjust themselves and make a deliberate effort and directed choices in response to technology and pedagogies in online teaching and learning in order to offer high-quality online education programs.

In this study, we examine the readiness of students for online learning as well as the level of support colleges of education managers, and tutors provide for the adoption and use of online teaching and learning tools given COVID-19 pandemic. Again, we look into the digital skills of students for online learning. The following research questions guide this study:

(1) How much has teaching and learning changed since COVID-19 pandemic? How much of the variance in students' readiness can be explained by the extracted online learning factors?

(2) How has institutional support promoted effective online teaching and learning?

(3) Do students have the digital skills for online learning?

(4) What are students' beliefs about online learning? What are the benefits and challenges students face in online learning? 
We use an online survey to gain quantitative as well as qualitative data for our study from which we identify the major issues that need to be addressed for a successful implementation of online learning. The results from this study will have profound implications for education policy in the colleges of education and starters who intend to set up online learning courses. We organise the rest of this study as follows: Section 2 identifies various works that relate to this study. Section 3 describes the methodology adopted for this study, followed by Section 4, which presents the findings of this study. We further discuss how institutions will leverage these results to improve online teaching and learning experience. Finally, we draw our conclusion and suggest future research in Section 5.

\section{Literature Review}

\subsection{Education Paradigm Shift and Promises of e-Learning}

E-learning system, otherwise known as Learning Management Systems (LMSs) allow learners to fit learning into their lifestyle. The quest for adopting LMSs in higher education emanates from the pedagogical design, flexibility on course content delivery and learner engagement with course materials from any geographical location.

The massive impact of e-learning technology on education globally as one of the achievements of the 21 st century cannot be overemphasised. The technology has minimised and is gradually eradicating face-to-face lesson delivery. Ritzhaupt, Dawson and Cavanaugh [3] assert that the use of technology within the educational sector has shifted teaching and learning from a teacher-centred to more student-centred approach. This shift has seen more individualised learning taking place than ever before. According to Otoo-Arthur and van Zyl [4], the adoption of e-learning in higher education dates back to the 60s and has developed from ComputerAssisted Learning through the multimedia courseware (computer-based and web-based training), smart learning environments, mobile and ubiquity learning to the augmented and virtual reality. Although there are many instances of the effective use of e-learning technology in some higher educational institutions (HEIs), problems have arisen where poor preparation failed to take into account user acceptance.

The integration of e-learning in higher education has brought flexibility to teaching and learning, putting the learner at the centre of the educational process. Nnazor [5] posits that advances in information and communication technology (ICT) have provided unprecedented opportunities for technology-facilitated synchronous and asynchronous teaching and learning on campus and in distance education environments.

A recent study shows that the COVID-19 pandemic is proving to be a constructive disruptor and has restructured the present conventional, classroom-based educational system [6]. This study which sought to find out enabling and impeding factors of digital reforms in optometry education revealed that a timely transition to online mode ensured continuity of education programs to its completion.

An interesting development emanating from the adoption of e-learning paradigm is the flexibility in extracting useful data to derive insights into how the teaching and learning environment can be optimised, hence the Big Data tag. Romero and Ventura [7], argue that these huge data generated can be studied to gain insight into students learning to improve educational outcomes and explain educational phenomena.

In terms of learning outcomes, Nae [8] pointed out that there is no significant difference between distance learning and the conventional classroom. Other authors have argued that online learning planned and managed successfully has always recorded better learning outcomes than the face-toface classroom-based learning [9]-[12].

e-Learning systems have quickly become an essential part of the infrastructure of classrooms and schools recently. From preschool to higher education, computers, laptops, smartphones, smartboards, and tablets have been embedded with instructional materials and software through which teachers and students could communicate, teach and learn. In the 21 st century, technology plays a role in every facet of education as students, teachers and administrators turn to their computers to access information, create and express themselves, communicate and collaborate, and track the achievement of learning outcomes. It is important to note that the impact of online learning environments continues to show positive results concerning learning outcomes. Adopting and implementing online teaching and learning technologies is imminent to colleges and the HEIs as a whole.

\subsection{Challenges and Pitfalls for Implementation of e-Learning}

The role of online education in this 21 st century as a vital model in transforming all the aspects of education and learning in the academic space cannot be overstressed in this pandemic period. The continuous adoption of the online education standard in many HEIs has been remarkable as many classrooms had to close down abruptly due to COVID-19. However, many educational institutions are still at the cradle of understanding and using these technologies to improve students learning 
experience. This e-learning comes with lots of challenges, if not well adopted and implemented could lead to disapproval. It is, therefore, imperative to ascertain the possible challenges and pitfalls that surround the implementation of e-learning to make it a success. In the West-African sub-region, substantial effort to adopt and implement these technologies has seen a little success over the past decade. These dilemmas have arisen due to individual characteristics, the characteristics of the technology and the institutional context [13]. Generally, the adoption of e-learning in the African context has been very slow, a problem attributed to the low level of investment in e-learning infrastructure, students attitudinal challenges, expensive data bandwidth, lack of trained instructors and minimal interaction time [14]-[16]. Lack of wireless networks, mobile devices and cloud-based technologies which help create new opportunities to restructure various educational areas including curriculum design, content delivery, content design, communication, collaboration, student services, classroom design and assessment are a challenge [17].

Watson [18] argues that communication technologies which do not support meaningful educational experiences, advances in information and communication technology (ICT) would not provide exceptional opportunities for technologyfacilitated teaching and learning on campus and in distance education environments. Kisanga and Ireson [19] also indicate other challenges including investments in technology such as hardware, software licenses, learning material development, equipment maintenance, and training of which many developing countries and their educational institutions are struggling to manage.

Presently, the growing risks students face as they spend more time interacting online cannot be overlooked. This interaction can expose students to online sexual exploitation, harmful and violent contents, and a greater risk of cyberbullying [20].

Otoo-Arthur and Van Zyl [21] point out that data management, data provenance, privacy, security, and confidentiality are essential issues that remain a challenge in e-learning. These they explain, emanate from the creation of massive data by users of the elearning systems. As education is changing from the conventional face-to-face to a more digitised learning system, finding ICT tools that apply secure data encryption, strong identity authentication and effective privacy policies will be useful for online education and learning [22]. Mu'Azu and Lawal [23] propose potential threats likely to breach the security and privacy of users. These threats, including unauthorised access, hacking/cracking, blackmailing for information disclosure, the act of human error and alteration of data and configuration among others they suggest may affect the usage of the elearning systems.

Horrigan [1], outlines five distinct digital readiness gaps into which people are likely to fall. These are digital-ready who are confident in their online skills. Cautious clickers who are less likely to engage in personal learning, either offline or online. However, they turn to the internet for some level of learning. The reluctant whose confidence with computers and other electronic devices is very low. The traditional group are usually active learners, but not very keen on using technology to pursue their learning. Part of which has to do with skills and trust. The final group is unprepared. They are not confident in their digital skills and do not have trust in any piece of online information.

Aldowah, Ghazal and Muniandy [24] opine that low confidence level of instructors, slow internet, lack of software application and poor ICT infrastructure are major challenges to the implementation of e-learning. Changing instructors culture background, and motivating them to use technology in teaching and learning are inherently a challenge [25].

Similarly, lack of quality e-content, awareness, high rate of illiteracy in computing, poor infrastructure and cultural barriers are other challenges that affect the adoption and implementation of e-learning systems [24], [26].

According to Mutisya and Makokha [27] heavy lecturer workloads, limited internet connectivity, denial of copyrights, inadequate ICT skills, lack of incentives, poor infrastructure and insufficient time for online interaction are serious challenges affecting the adoption of e-learning. These challenges, the authors state evolve from inadequate financial resource and commitment of instructors if well addressed, will increase the demand for e-learning in higher education.

Shindina et al. [26], in their study, identify student motivation and digital divide among teachers and students to be an emerging challenge for the elearning paradigm. Students are easily distracted and are likely to drop out of online courses. Motivating students by creating the right electronic educational environment will heavily depend on the teacher. The study further suggests effective communication between the teacher and students, and the provision of technical support as vital to motivate students in an online programme. Teachers, therefore, need to be abreast with new technologies to attract students to online courses to minimise the attrition rate.

Aldowah, Al-Samarraie and Ghazal [28] pointed out that the design of the course, the support provided, society/culture, and technology have a significant impact on the instructors' use of elearning systems. These issues tend to affect the way students will respond to the use of e-learning systems. 
Other challenges include the difficulty in tracking and the number of students, participating in the web conferences and activating students, who are more invisible than in face-to-face lectures [29]. Similarly, Rensburg [30] asserts that, although online teaching and learning practices can enhance student satisfaction and retention, infrastructure and insituational support if not checked, will hinder these positive outcomes.

Conducting a standard test at the end of the semester by HEIs was another challenge during the pandemic period [31]. Online examinations introduced several challenges, such as student impersonation and copying of content from the internet, which is an ethical concern that HEIs has to resolve.

\subsection{Making Online Learning Successful}

Higher education institutions are bound to adapt to the dynamic demands, tools, and other technological changes [32]. This adaptation to technological changes they suggest is inevitable unless the institution sees it as irrelevant. ICT has, therefore, become a benchmark in managing online teaching and learning processes, for which the teacher is ultimately responsible. Teachers knowledge, integration of ICT in lesson delivery, structure and ICT competence are important factors that support the successful delivery of online education [33]. Locketz [34] posits that to ensure effective and quality online teaching and learning, management of an educational institution must be frontiers in planning, promoting, motivation and supporting to develop a strong policy to guide both teaching and learning. Institutional managers and administrators must take bold steps towards achieving quality online learning to support both teachers and students. Management must understand the roles and their impact on online learning. Dawson and Cavanaugh [3], suggests that developing a written policy and the provision of internet infrastructure will support and encourage the faculty and learners to develop the right attitude towards online teaching and learning.

Mahajan [35] makes a case for blended learning and puts forth a model which promises to provide a more satisfying experience for students. Blended learning makes education more accessible and flexible for students to engage from home whiles, benefiting from the conventional face-to-face interactions. This method increases students' satisfaction, promotes deeper learning and reduces stress.

Another way of improving students' satisfaction in online learning, as suggested by Martínez-Jiménez and Ruiz-Jiménez [36], is through the online flipped learning methodology. This approach will offer more opportunities for students to develop critical and independent thinking and to enhance their learning processes by collaborative interaction with peers.

Jansen, van Leeuwen, Janssen, Conijn and Kester [37] suggest that a typical e-learning system presents students with great autonomy over their learning process. As a result, students often struggle to selfregulate their learning. They, therefore, concluded that self-regulated activities should be considered to ensure the implementation of successful e-learning model.

Giddens, Curry-Lourenco, Miles and Reeder [38] show that creating a virtual community that support narrative pedagogy, highly engaging student-centred learning and requirement for students to apply content within a real-world context is vital for successful online learning.

Abe [39] presents a Five-Factor Model of Personality (FFM) and linguistic styles with measures of academic performance in fully online asynchronous classes. The findings show that conscientiousness, openness to experience and analytic thinking were associated with successful online learning.

Developing a community of inquiry framework has been identified as a major approach to successful e-learning implementation [40]. This community does not only provide support only on the use of elearning applications but ensures effective collaboration on best practices.

Otoo-Arthur and van Zyl [4] point out that data generated from e-learning systems are useful for learning analytics. To this end, they proposed a scalable and adaptable framework for e-Learning which could be used to extract useful insights from students learning behaviour. These insights could be used to give feedback to both students and tutors for improving the learners' experience as well as the elearning system. Similarly, Thomson [41] show that frequent and prompt feedback, clear communication and concise instructions are significant attributes students found to be important in their online courses.

Collaboration, teamwork satisfaction, and students' attitudes toward online learning are other important factors that promote active online education and learning. Ku, Wei and Akarasriworn [42] found out that students, when allowed to work in teams, encouraged collaborative learning in an online environment. Their study revealed that students' attitude, team dynamics, team acquaintance and instructor support are significant factors that crystallize into effective online learner experience.

\section{Methodology}

The analysis of this study is based on a survey conducted from March 1 to August 30, 2020, among 506 respondents from all the forty-six (46) public colleges of education in Ghana with less than two (2) 
years experience learning online. The survey was conducted online by the researchers. In order to have a picture of the level of preparedness of students of colleges of education for online learning, we administered a set of questions (including both closed and opened ended forms). The following shows the general characteristics of the participants for this study.

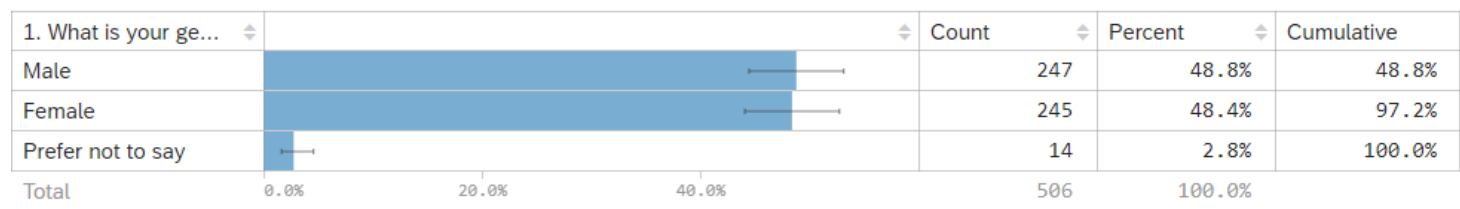

Figure 1. Gender distribution of participants shows a balance in the respondents of the survey. Although $97.2 \%$ indicated their gender, $2.8 \%$ of the participants prefer not to say

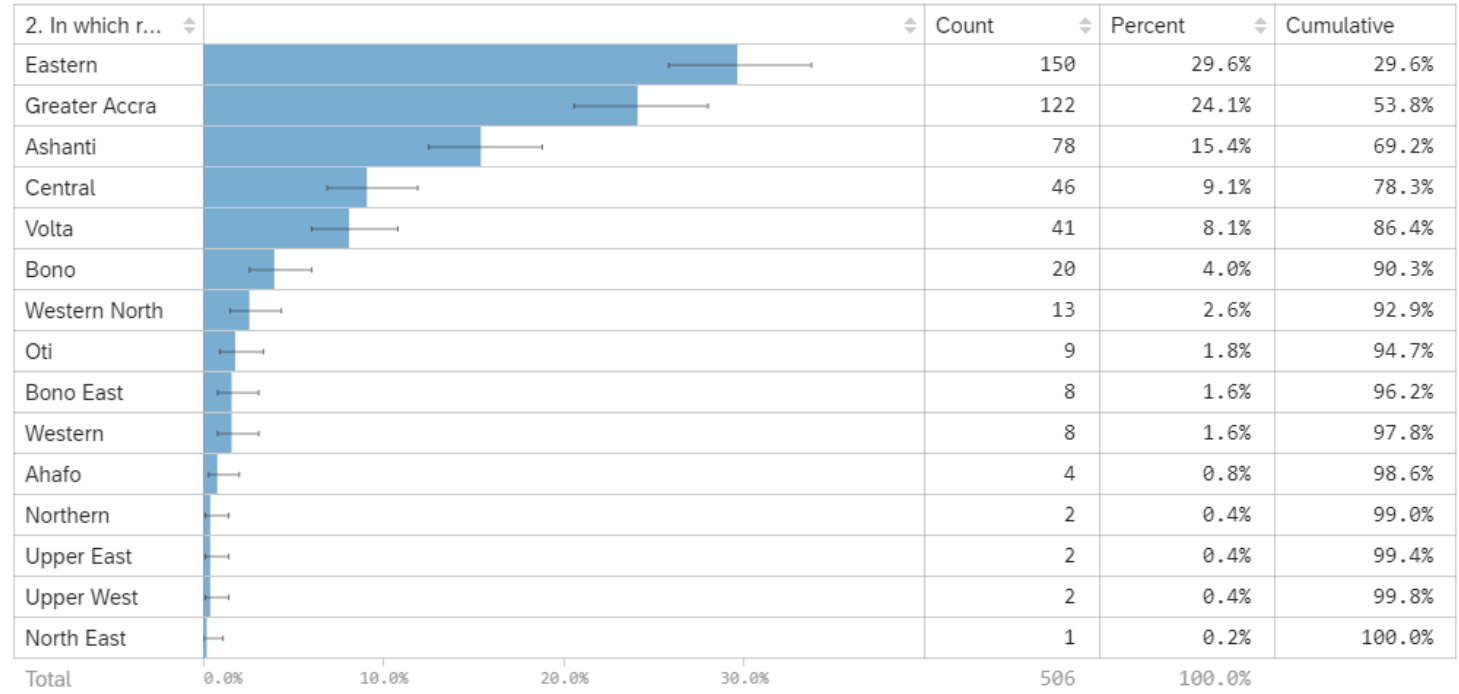

Figure 2. Regional distribution of participants showing responses from 15 out of 16 Regions of Ghana. About a third $(12.1 \%, \mathrm{n}=61)$ of the participants were from the northern sector of the country. The rest $(87.9 \%, \mathrm{n}=445)$ were from the sub-region

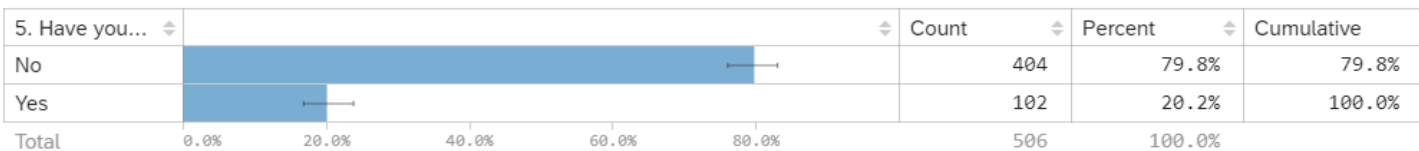

Figure 3. Most of the participants $(79.80 \%, n=404)$ do not have prior usage of online learning. Few students $(20.20 \%, \mathrm{n}=102)$ however indicated that they were learning online before COVID-19

\begin{tabular}{|c|c|c|c|c|c|}
\hline 7. Which online platform/Lea... $\Rightarrow$ & Checked Percent & . & $\Leftrightarrow$ & Checked Co... $\Rightarrow$ & Sample Size \\
\hline Google Classroom & & $\longmapsto$ & $33.4 \%$ & 169 & 506 \\
\hline Moodle & & $\longmapsto$ & $30.4 \%$ & 154 & 506 \\
\hline Other & & $\longmapsto$ & $28.1 \%$ & 142 & 506 \\
\hline LMS developed by my institution & & 一 & $17.4 \%$ & 88 & 506 \\
\hline None & $\longmapsto$ & & $10.7 \%$ & 54 & 506 \\
\hline Blackboard & $\longrightarrow$ & & $4.3 \%$ & 22 & 506 \\
\hline I don't know & 一 & & $2.6 \%$ & 13 & 506 \\
\hline Sakai & 一 & & $1.2 \%$ & 6 & 506 \\
\hline
\end{tabular}

Figure 4. Several notable LMS technologies currently employed in e-learning at the colleges of education. We see two common LMS (Google Classroom and Moodle) driving online learning 
Table 1. Other characteristics of the participants of this survey. Whiles participants in JHS Education programme recorded the highest $(64.62 \%, \mathrm{n}=327)$ participation most of them indicated less involvement in online learning

\begin{tabular}{lll}
\hline Characteristics & $\mathbf{N = 5 0 6}$ & Percent $(\boldsymbol{\%})$ \\
\hline 3. Programme of Study & & \\
\hline Early Childhood & 44 & 8.70 \\
Primary Education & 135 & 26.68 \\
JHS Education & 327 & 64.62 \\
\hline 4. No. of years spent in College & & \\
\hline Less than 1 & 29 & 5.80 \\
One (1) & 167 & 33.00 \\
Two (2) & 286 & 56.50 \\
Three (3) or more & 24 & 4.70 \\
6. No. of years students have been learning online & & \\
\hline 0-2 & 478 & 94.50 \\
3-5 & 20 & 4.00 \\
6-8 & 4 & 0.80 \\
9 or More & 4 & 0.80 \\
\hline
\end{tabular}

We took a broad view of the open-ended responses from the samples from the colleges. We captured issues that are likely to challenge the smooth implementation of online learning. From these responses, we extract the frequency of keywords, phrases and sentences more likely to address the levels of preparedness to deliver online learning using a model to cluster the various issues for analysis, for which Term Frequency - Inverted Document Frequency (TF-IDF) has been proposed [43]. We used a token separation and counting algorithm Natural Language Tool Kit (NLTK) software to perform this task. Weighted frequencies of key terms were then computed using the TF-IDF relevance method across the entirety of the target responses. Words occurring with higher frequency in the overall responses than in the target responses were excluded from consideration, as these were deemed to represent general terms rather than scope related theme terms (issues).

\section{Results}

The results section presents the major findings and summary of key analytical points of the survey - our analysis detail critical issues concerning the preparedness of students for online learning given COVID-19. We discuss the results under three (3) themes: shifting to online learning, institutional support and basic online learning skills.

\subsection{Teaching and Learning during COVID-19 Pandemic - Shifting to Online Learning}

The majority $(83.00 \%, \mathrm{n}=420)$ of the students who participated indicated that they had to shift their face-to-face interaction to online as a result of COVID-19. This result shows how urgent students had to adapt to the online learning platform in order to complete the rest of their semester's activities.

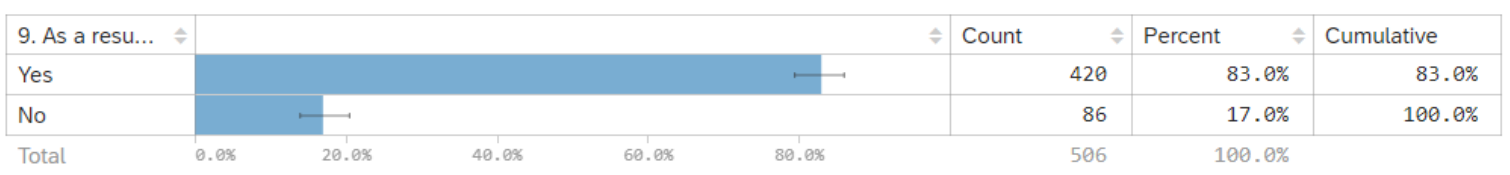

Figure 5. Shifting to Online Learning due to COVID-19

The number of days given to students to prepare for online learning was limited. The time allotted for preparation was not enough to keep students effectively in the online learning process. This outcome confirms the results indicated by students
(94.50\%, $\mathrm{n}=478$ ) in Figure 6 on the time interval given for preparation to transition to online learning. Most participants indicated they were given short notice to transition online with a median of 7 as in Table 2. 


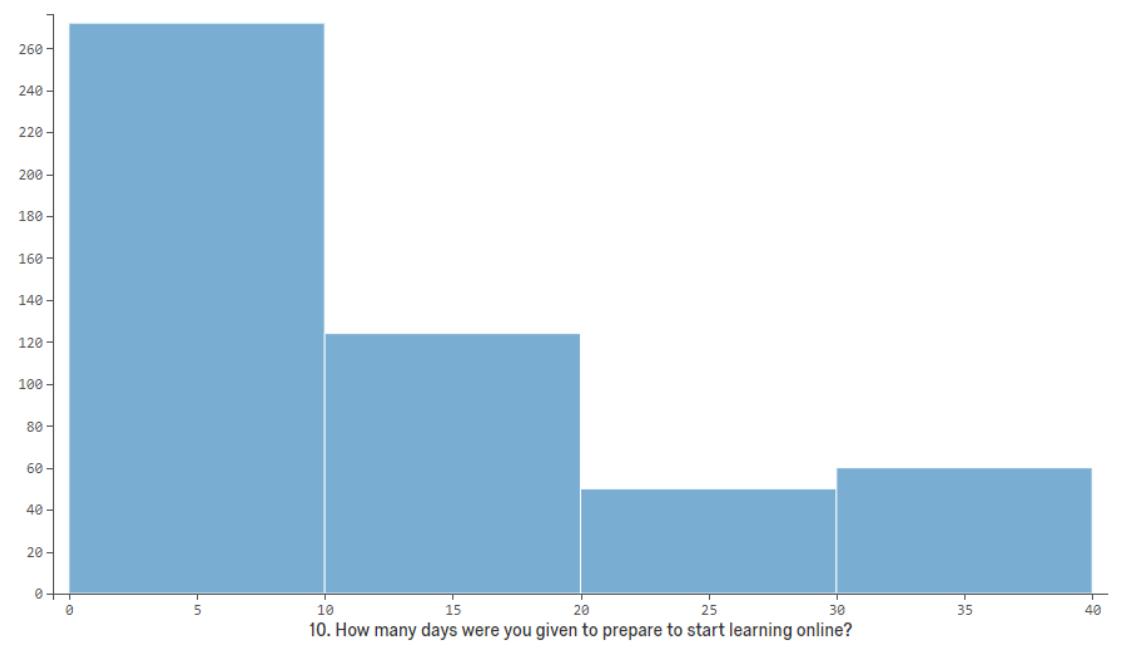

Figure 6. The number of days given to students to prepare for learning online was very limited. Many of the students had to do so within a week

Table 2. Continuous summary of students' preparation for e-learning

\begin{tabular}{cccccccc}
\hline Sample Size & Median & Average & $\begin{array}{l}\text { Confidence Interval of } \\
\text { Average }\end{array}$ & $\begin{array}{l}\text { Standard } \\
\text { Deviation }\end{array}$ & Min & Max & Sum \\
\hline 506 of 506 & 7.0 & 12.83 & 12.15 to 13.50 & 7.76 & 7.0 & 30.0 & 6490 \\
\hline
\end{tabular}

We observed that only $25 \%$ of the learning resources for students were initially available online. This result was a clear indication that tutors preparation to provide teaching support for students online was very low as well. Students indicated their preference for face-to-face. Insufficient resources from the tutors were a major hindrance to effective learning online during the pandemic period.

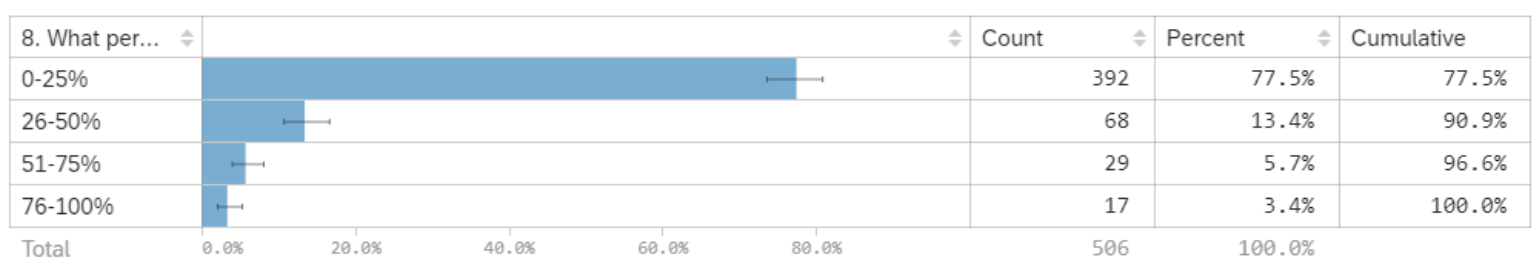

Figure 7. Initial course resources available online for students is minimal

\subsection{Institutional Support}

The complex nature of developing and implementing e-learning can be daunting. Support is, therefore, critical to ensure smooth implementation. Our study shows that most of the colleges are not providing enough support for students. Most participants (62.3\%, $\mathrm{n}=315$ and $63.2 \%, \mathrm{n}=320)$ indicated their college do not have clear vision and objectives for online learning. They $(84 \%, n=290)$ also indicated that their environment is not supportive enough for online learning. These responses indicate how most of the colleges of education in Ghana seem not to have prepared for pandemics like COVID-19. Hence, very little attention was paid to the transitioning to online as there were no structures in place to provide support for students in this pandemic era. Again, we noticed there was no strategy put in place by the managers of the college to train students. We see from Figure 13 some $63.8 \%$ of the participants indicated they were not adequately trained to transition online. The frustration of getting technical support for learning online was very high, with $69.8 \%$ of the students indicating that their institution did not provide the needed support (see Figure 14). 


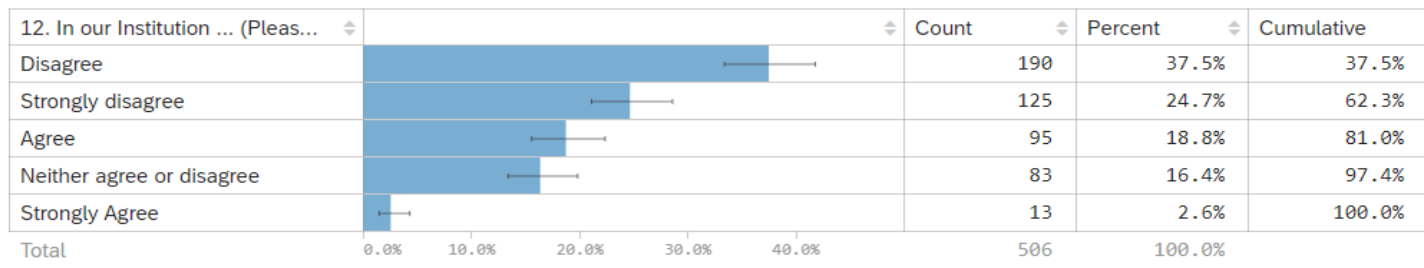

Figure 8. There is a clear vision for online learning

\begin{tabular}{|c|c|c|c|c|}
\hline 12. In our Institution ... (Pleas... & $\Rightarrow$ & Count & Percent & Cumulative \\
\hline Strongly disagree & $\longmapsto$ & 270 & $53.4 \%$ & $53.4 \%$ \\
\hline Disagree & $\longmapsto$ & 157 & $31.0 \%$ & $84.4 \%$ \\
\hline Neither agree or disagree & 一 & 38 & $7.5 \%$ & $91.9 \%$ \\
\hline Agree & 一 & 29 & $5.7 \%$ & $97.6 \%$ \\
\hline Strongly Agree & - & 12 & $2.4 \%$ & $100.0 \%$ \\
\hline
\end{tabular}

Figure 9. There is a supportive environment as regards internet data and smart tools for online learning

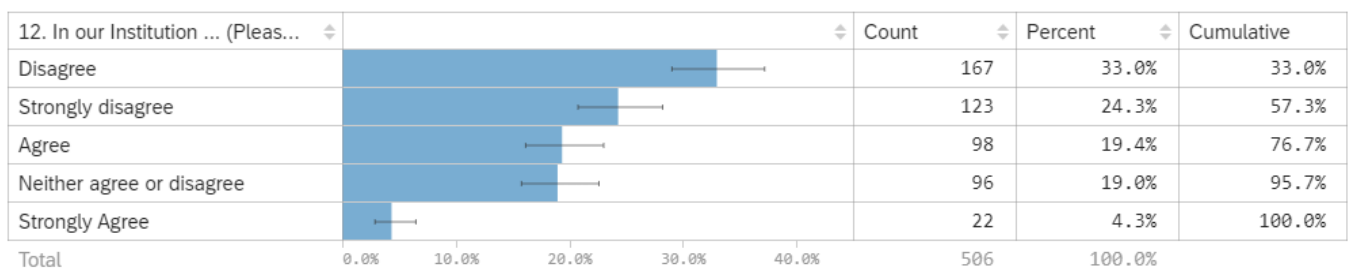

Figure 10. There are clear objectives as regards online learning

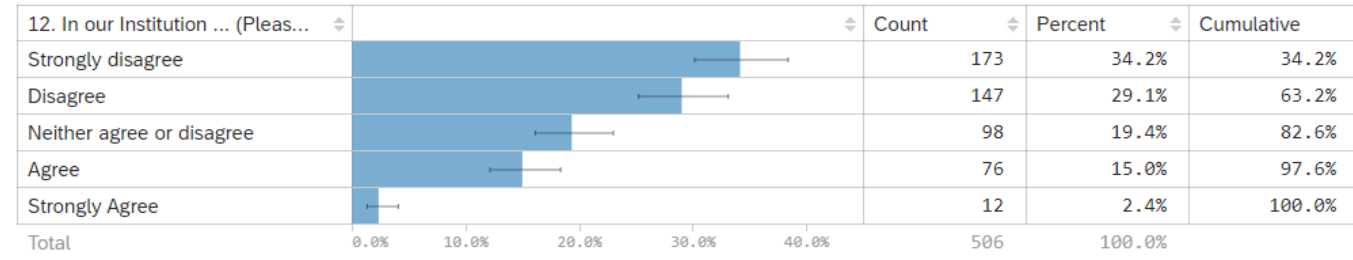

Figure 11: Attention is paid to the student change processes inherent in changing to online learning

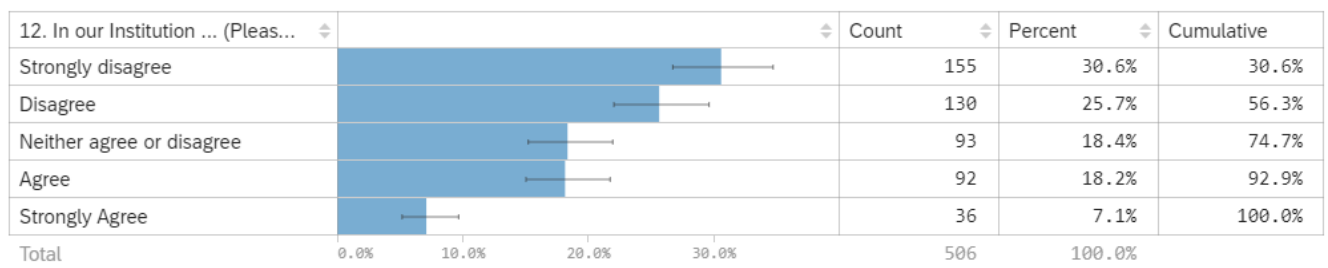

Figure 12. There is a strategy to train students towards online learning

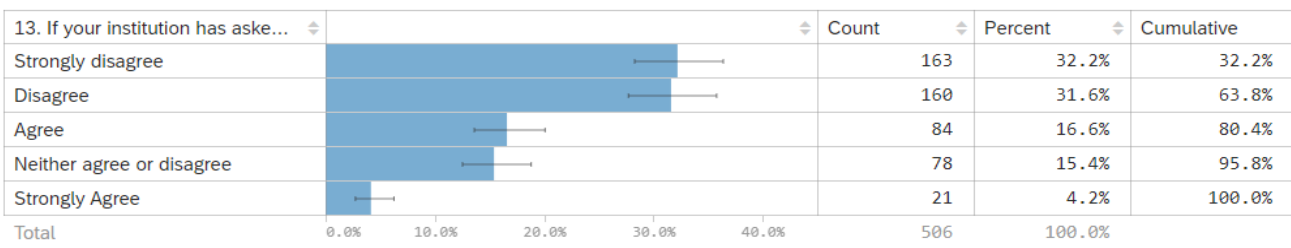

Figure 13. Training on the use of the LMS

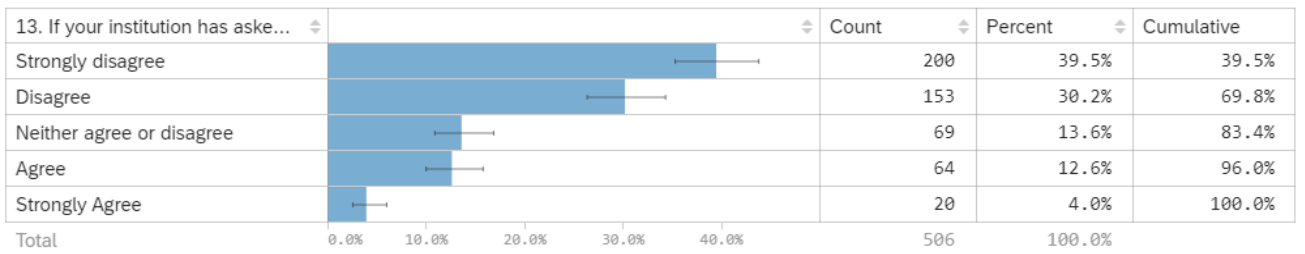

Figure 14. Additional technical support to transition because of COVID-19 


\subsection{Digital Skills for Online Learning}

Figures $15-18$ show students' responses to digital skills and online learning.

\begin{tabular}{|c|c|c|c|c|c|}
\hline 14. Overall, I ... [... view cours... $\Rightarrow$ & & 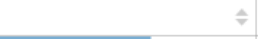 & Count & Percent & Cumulative \\
\hline Agree & & $\longmapsto$ & 205 & $40.5 \%$ & $40.5 \%$ \\
\hline Neither agree or disagree & $\longmapsto$ & & 103 & $20.4 \%$ & $60.9 \%$ \\
\hline Strongly disagree & $\longmapsto$ & & 76 & $15.0 \%$ & $75.9 \%$ \\
\hline Strongly Agree & $\longmapsto$ & & 64 & $12.6 \%$ & $88.5 \%$ \\
\hline Disagree & $\longmapsto$ & & 58 & $11.5 \%$ & $100.0 \%$ \\
\hline
\end{tabular}

Figure 15. I can view course resources such as presentation slides, notes, videos

\begin{tabular}{|c|c|c|c|c|}
\hline 14. Overall, I ... [... can see my $\ldots$. & 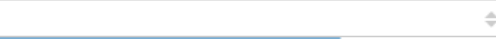 & Count & Percent & Cumulative \\
\hline Strongly disagree & $\longmapsto$ & 142 & $28.1 \%$ & $28.1 \%$ \\
\hline Disagree & $\longmapsto$ & 120 & $23.7 \%$ & $51.8 \%$ \\
\hline Agree & $\longrightarrow$ & 111 & $21.9 \%$ & $73.7 \%$ \\
\hline Neither agree or disagree & $\longmapsto$ & 102 & $20.2 \%$ & $93.9 \%$ \\
\hline Strongly Agree & $\longrightarrow$ & 31 & $6.1 \%$ & $100.0 \%$ \\
\hline
\end{tabular}

Figure 16. I can see my course

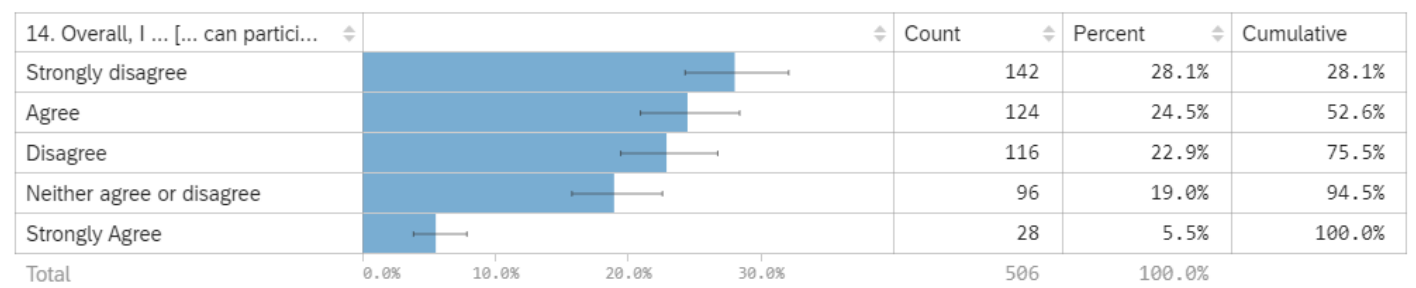

Figure 17. I can participate in group work

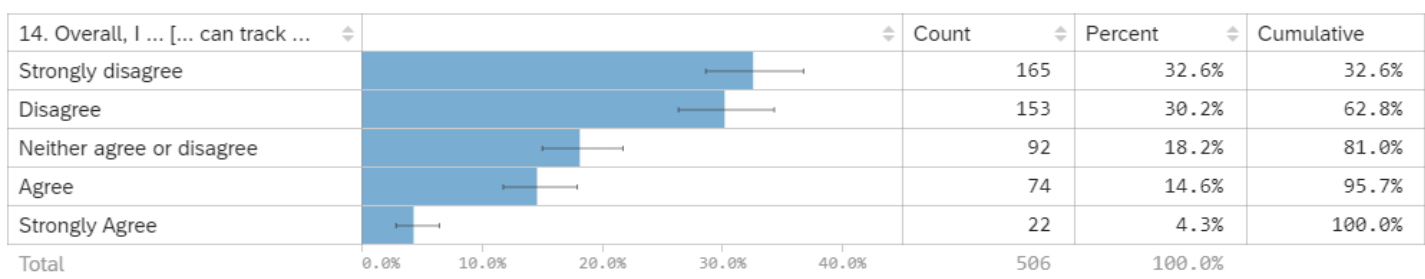

Figure 18. I can track my progress

Table 3 shows what students believe to be the benefits of online learning. Column 1 shows each of the terms (including variants) with the number of occurrences of that term across all survey question and the number of responses in which it occurs. Column 2 shows the TF-IDF value for that term, within the target set and the relevance of that term is shown in column 3 . The table entries are sorted in order of descending TF-IDF values and its corresponding values. The lower the TF-IDF value, the relevance of the benefits to the student. This interpretation holds the same for the challenges indicated by students in Table 4 .

Table 3. Results for the Term Frequency analysis showing the four (4) most relevant benefits of online learning to the students

\begin{tabular}{|l|l|l|}
\hline Term (Benefit) & \multicolumn{2}{|l|}{ Frequency Measures } \\
\hline (No. of Occurrences; No. of Responses) & TF-IDF & Relevance \\
\hline Own pace learning $(157,125)$ & 1.47 & 184 \\
\hline Cognitive development $(28,27)$ & 3.00 & 81 \\
\hline Digital skills $(20,19)$ & 3.40 & 65 \\
\hline Research skills $(14,14)$ & 3.59 & 50 \\
\hline
\end{tabular}


Table 4. The results for the Term Frequency analysis showing the six (6) most relevant challenges worth addressing for successful online learning

\begin{tabular}{|c|l|l|}
\hline Term (Challenge) & \multicolumn{2}{|c|}{ Frequency Measure } \\
\hline $\begin{array}{c}\text { (No. of Occurrences; No. of } \\
\text { Responses) }\end{array}$ & TF-IDF & Relevance \\
\hline $\begin{array}{c}\text { Network (Connectivity) } \\
(268,247)\end{array}$ & 0.66 & 181 \\
\hline Cost (251,192) & 0.90 & 176 \\
\hline Computer/laptops (45,33) & 3.30 & 109 \\
\hline Institutional support (30,26) & 3.26 & 85 \\
\hline Health issue (2,2) & 5.53 & 11 \\
\hline Electricity (2,2) & 5.53 & 11 \\
\hline
\end{tabular}

Table 5. Mean, Median, and Standard Deviation of Results

\begin{tabular}{|c|c|c|c|c|}
\hline $\begin{array}{l}\text { Learning } \\
\text { COVID19 }\end{array}$ & Online $\quad$ During & $\begin{array}{l}\text { Institutional } \\
\text { Support } \\
\text { score }\end{array}$ & Online_Skill & $\begin{array}{l}\text { Overall } \\
\text { readiness }\end{array}$ \\
\hline \multirow{4}{*}{ No } & Mean & 3.4683 & 3.4856 & 2.5952 \\
\hline & $\mathrm{N}$ & 404 & 404 & 404 \\
\hline & Median & 3.4000 & 3.5000 & 2.5889 \\
\hline & Std. Deviation & .89203 & .83536 & .49899 \\
\hline \multirow[t]{4}{*}{ Yes } & Mean & 3.3039 & 3.2108 & 2.4461 \\
\hline & $\mathrm{N}$ & 102 & 102 & 102 \\
\hline & Maximum & 5.00 & 5.00 & 3.67 \\
\hline & Std. Deviation & .90005 & .79635 & .48907 \\
\hline \multirow[t]{4}{*}{ Total } & Mean & 3.4352 & 3.4302 & 2.5651 \\
\hline & $\mathrm{N}$ & 506 & 506 & 506 \\
\hline & Median & 3.4000 & 3.4167 & 2.5611 \\
\hline & Std. Deviation & .89519 & .83420 & .50013 \\
\hline
\end{tabular}

\section{Discussion}

\subsection{Teaching and Learning during COVID- 19 (Students' Readiness for Online Learning)}

Our findings show a massive shift from the conventional face-to-face classroom to online education. This sudden change forced by COVID-19 has amplified the e-learning mania, which seems to have caught up with every level of education.

The independent samples $t$-test result for the two groupings (institutional readiness and online skill readiness) is shown in Table 6 . In table 6 , the $p$-value of the mean score of the responses corresponding to both groups is $0.078(\mathrm{p}<0.10)$ and $0.005(\mathrm{p}<0.05)$ which shows that the difference in mean scores between the groups is statistically significant.

\subsection{Institutional Support}

The results of this study revealed several factors that affect students' readiness for online learning. The prevalence of infrastructural challenge was evident in students' responses. Like other subSaharan countries, teaching and learning online in the Ghanaian college of education have been hampered by an infrastructural gap (connectivity, high internet cost, lack of computer and electricity). According to Kapasia et al. [44], poor internet connectivity and unfavourable study environment are challenges students from remote areas, and marginalized sections face. This case is no exception in Ghana. Similarly, Mutisya and Makokha [27] suggest that poor internet connectivity coupled with low bandwidth where internet connectivity poses a serious challenge to the adoption of e-learning in higher education. 
Table 6. Independent samples t-test result Independent Samples Test

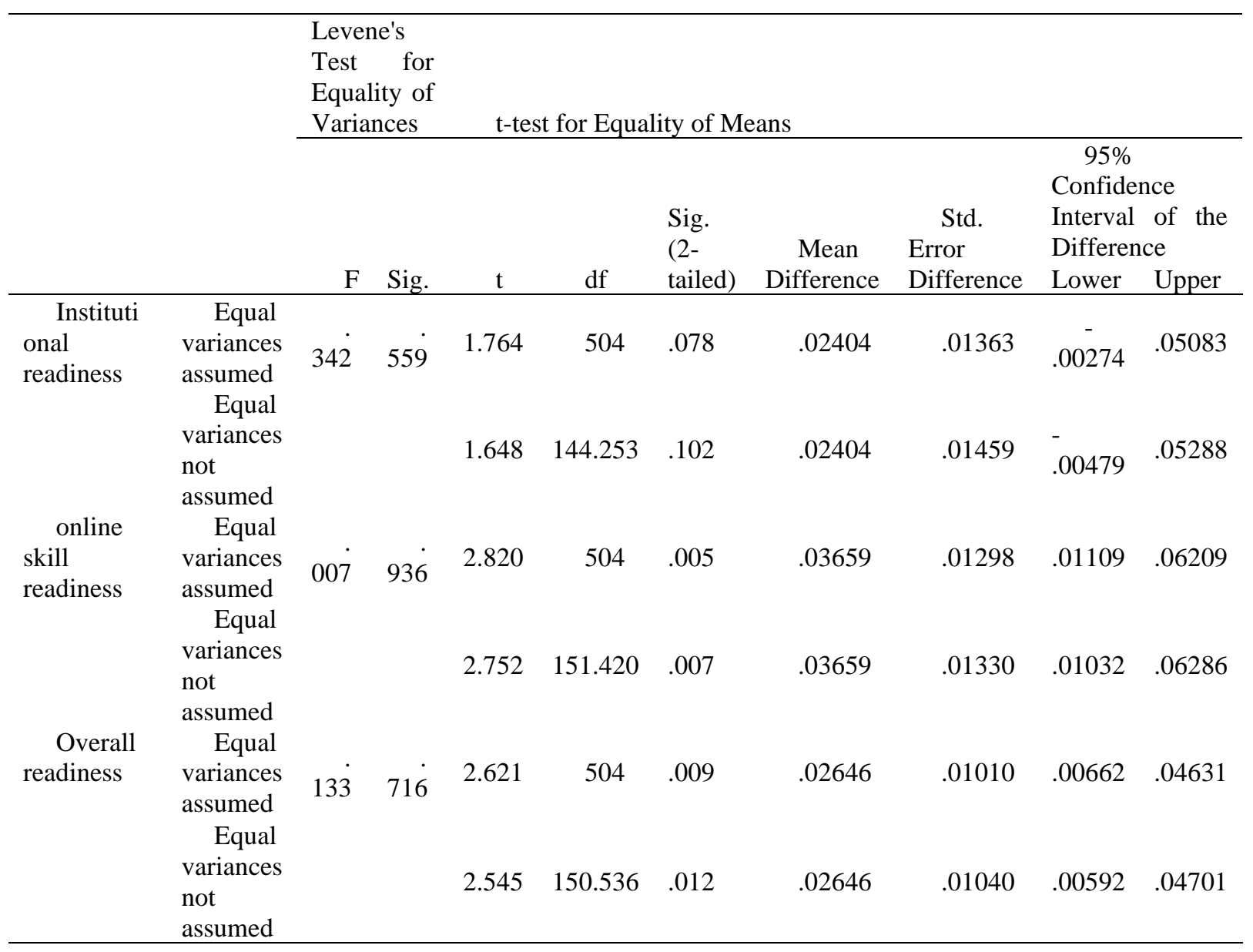

Connectivity is critical in online learning, as it provides the basis for teaching and learning interactivity in online learning. Network connectivity was a major issue that affected students' effective participation in online learning, recording a TF-IDF value of 0.66 . This result was similar to findings suggested by by Mutisya and Makokha [27] to affect the adoption of e-learning. Another issue that emanated from their responses was the financial commitment on the part of their parents to purchase devices to support their learning online. The provision of reliable computers/laptops is essential to e-learning. Failure to address this issue, among others, has the potential of derailing the successful implementation of the e-learning within the various colleges.

In general, we found out that most of the colleges were not providing enough support. Besides, inadequate training on the use of online learning tools was growing concerns that characterised the implementation. Online students need help to be successful online learners, and this could include social, academic, and cognitive forms of support [40].

\subsection{Students' digital skills and online learning}

Students limited ICT skills was another challenge that obstruct the utilization of e-learning among the colleges of education in Ghana. Understanding the learner characteristics and digital skills are an essential factor for successful online learning. Effective use of tech tools and internet for personal learning, therefore, is very useful to boost the confidence of students in learning online. Our findings show that students were digitally wary and found it difficult to perform basic online learning task. Most of the participants $(59.5 \%)$ were not familiar with viewing course slides, notes and videos while few students could navigate around for their courses of study. Only $30.0 \%$ of the participants could participate in group work, and some $18.9 \%$ 
could track their progress. Despite the fact that various institutions had some plans to train and support students for online learning, the limited space for students to transition online could not make it happen.

\subsection{Students' Beliefs about online learning during COVID-19}

5.4.1. E-Learning Benefits. The sudden disruption to the educational space due to COVID-19 pandemic has generated a surge in demand for online teaching and learning. Evidence from this study shows that the adoption of the online learning model has significantly improved access, digital skills and literacy. A majority $(83 \%, \mathrm{n}=420)$ of the respondents indicated shifting to online due to COVID-19 pandemic. When asked about what students considered as the top four benefits of online learning, their comments in order of relevance included: 1) own pace learning (Relevance $=184), 2$ ) cognitive development concerning knowledge and problemsolving dispositions (Relevance $=81$ ), 3) digital skills (Relevance $=65$ ), and 4) research skills (Relevance $=50$ ). Studies point out some of the benefit and how it bridges the digital skill gap whiles providing flexible teaching and learning experience. Iivari et al. [45] assert that enhanced support from teachers and parents will have positive impact on the online learning process. According to Kamba [15], elearning is self-paced, offer consistent content, faster and works anytime and anywhere for the student.

5.4.2 E-Learning Challenges. Our results showed a marginal increase in access and digital literacy. However, the adoption has equally introduced a gap, especially to the underserved and vulnerable. Students when asked about what students considered as top six challenges of online learning, their comments in order included:

1) connectivity $($ Relevance $=181)$,

2) cost of internet data (Relevance $=176)$, computer (laptops/tablets/smartphones - Relevance $=109$ ) institutional support (Relevance $=109$ ), health issues and electricity (Relevance $=11$ respectively).

This result is in consistent with findings from a study by Rajhans et al. [6]. Their study outlined uninterrupted internet connectivity, technical disturbances in apps, students' orientation, pace of learners among others. The transformation to quickly adopt and adapt has brought a lot of burden on institutions and individual students.

\section{Recommendation}

The researchers recommend the formulation of elearning policies to guide the implementation of online education which has come to stay with us. HEIs should make it a priority to augment government's support by funding e-learning in terms of infrastructural provision, research, awareness creation and attitude change. Again, the provision of laptops or tablets for students will be a booster to strengthen online education, of which parents' commitment in this area is critical.

\section{Conclusion}

The COVID-19 pandemic has ignited a sudden choice of implementing online education in Ghanaian schools. However, the adoption and implementation of e-learning in Ghanaian schools are not encouraging. This study examines the readiness of students in embracing the online learning paradigm in a pandemic outbreak and the immediate attention needed to support students to transition online. We noted students were slow to adapt to online education due to policy unresponsiveness, lack of technical infrastructure and support from HEIs as they are already grappling with financial support from the government. The adoption and implementation of technology in education lie heavily on the government and leaderships of educational institutions. Governments should make firm commitments to provide funding and infrastructural support in order to advance online education and learning. Developing a helpline can take care of all the needs of the students enrolled in various educational institutions.

Our ongoing work focuses on the assessment of managers of HEIs and instructors' readiness to facilitate the online learning process and its impact on transitioning from conventional face-to-face teaching and learning to online education on the performance of students.

\section{References}

[1] J. B. Horrigan, "Digital readiness gap," Pew Res. Cent., no. September, p. Digital Readiness Gaps, 2016.

[2] E. Dahlstrom, D. C. Brooks, and J. Bichsel, "The Current Ecosystem of Learning Management Systems in Higher Education: Student, Faculty, and IT Perspectives," Educ. Res. Rep., no. September 2014, p. 27, 2014.

[3] A. D. Ritzhaupt, K. Dawson, and C. Cavanaugh, "An Investigation of Factors Influencing Student Use of Technology in K-12 Classrooms Using Path Analysis," vol. 46, no. 3, pp. 229-254, 2012.

[4] D. Otoo-Arthur and T. L. van Zyl, "A scalable heterogeneous big data framework for e-learning systems," 
in 2020 International Conference on Artificial Intelligence, Big Data, Computing and Data Communication Systems, icABCD 2020 - Proceedings, 2020.

[5] R. Nnazor, "A conceptual framework for understanding use of information and communication technology in teaching in universities," Citeseer, vol. 6, pp. 47-58, 2009.

[6] V. Rajhans, U. Memon, V. Patil, and A. Goyal, "Impact of COVID-19 on academic activities and way forward in Indian Optometry," J. Optom., 2020.

[7] C. Romero and S. Ventura, "Data mining in education," Wiley Interdiscip. Rev. Data Min. Knowl. Discov., vol. 3, no. 1, pp. 12-27, 2013.

[8] N. Nae, "Online Learning During The Pandemic: Where Does Japan Stand." Euromentor Journal, XI, 2020.

[9] K. L. Smart and J. J. Cappel, "Students' Perceptions of Online Learning: A Comparative Study," J. Inf. Technol. Educ. Res., vol. 5, pp. 201-219, 2006.

[10] M. Hannay, "Perceptions of Distance Learning: a Comparison of Online and Traditional Learning," vol. 2, no. 1 , pp. $1-11,2006$

[11] A. Y. Ni, "Comparing the Effectiveness of Classroom and Online Learning: Teaching Research Methods," $J$. Public Aff. Educ., vol. 19, no. 2, pp. 199-215, 2013.

[12] D. James, "E-learning Versus Classroom Activities: Student Preferences in a Japanese University," pp. 116126, 2020.

[13] P. J. Hu, P. Y. K. Chau, O. R. Liu Sheng, and K. Y. Tam, "Examining the Technology Acceptance Model Using Physician Acceptance of Telemedicine Technology," J. Manag. Inf. Syst., vol. 16, no. 2, pp. 91112, 2015.

[14] D. Hollow, "eLearning in Africa: Challenges priorities and future direction," no. Trucano 2005, 2009.

[15] M. A. Kamba, "Problems, Challenges and Benefits of Implementing E-learning in Nigerian Universities: An Empirical Study," Int. J. Emerg. Technol. Learn., pp. 6669, 2009.

[16] J. P. Kasse and W. Balunywa, "An assessment of elearning utilization by a section of Ugandan universities : challenges , success factors and way forward," in International conference on ICT for Africa, 2013.

[17] V. S. Chomal, "A study and analysis of paradigm shifts in education triggered by technology," Int. J. Res. Econ. Soc. Sci., vol. 3, no. 1, pp. 14-28, 2013.

[18] D. M. Watson, "Research tells us about problems inhibiting teacher use of IT. In Capacity Building for IT in Education in Developing Countries: IFIP TC3 WG3. 1, 3.4 \& 3.5 Working Conference on Capacity Building for IT in Education in Developing Countries 19-25 August 19,' 2013, p. 185.
[19] D. Kisanga and G. Ireson, "Barriers and strategies on adoption of $\mathrm{e}$ - learning in Tanzanian higher learning institutions: Lessons for adopters," Int. J. Educ. Dev. Using Inf. Commun. Technol., vol. 11, no. 2, pp. 126-137, 2015.

[20] UNESCO, "United Nations Sustainable Development. 2020. Education.," 2020. https://www.un.org/sustainable development/education/. (Access Date: 22-Aug-2020).

[21] D. Otoo-Arthur and T. Van Zyl, "A systematic review on big data analytics frameworks for higher education Tools and algorithms," in ACM International Conference Proceeding Series, 2019.

[22] D. Andrade, "How to Address Data Privacy During Remote Learning," 2020.

[23] A. A. Mu'Azu and I. A. Lawal, "E-learning system vulnerabilities: Threats and promises for students' information system," 2012 IEEE Symp. E-Learning, EManagement E-Services, IS3e 2012, pp. 17-22, 2012.

[24] H. Aldowah, S. Ghazal, and B. Muniandy, "Issues and Challenges of Using E-Learning in a Yemeni Public University," Indian J. Sci. Technol., vol. 8, no. 32, pp. 1-9, 2015.

[25] A. Al-adwan and J. Smedley, "Implementing elearning in the Jordanian Higher Education System: Factors affecting impact.," Int. J. Educ. Dev. using Inf. Commun. Technol., vol. 8, no. 1, pp. 121-135, 2012.

[26] T. Shindina, N. Kniazena, N. Usmanova, and N. Orlova, "E-Learning: Experience and New Challenges," 2020 5th Int. Conf. Inf. Technol. Eng. Educ. Inforino 2020 - Proc., pp. 0-3, 2020.

[27] D. N. Mutisya and G. L. Makokha, "Challenges affecting adoption of e-learning in public universities in Kenya," E-Learning Digit. Media, vol. 13, no. 3-4, pp. 140-157, 2016.

[28] H. Aldowah, H. Al-Samarraie, and S. Ghazal, "How Course, Contextual, and Technological Challenges are Associated with Instructors' Individual Challenges to Successfully Implement E-Learning: A Developing Country Perspective," IEEE Access, vol. 7, pp. 4879248806, 2019

[29] C. Andersson and G. Kroisandt, "Opportunities and challenges with e-learning courses in statistics for engineering and computer science students," EDUNINE 2018 - 2nd IEEE World Eng. Educ. Conf. Role Prof. Assoc. Contemp. Eng. Careers, Proc., pp. 2018-2021, 2018

[30] E. S. Janse van Rensburg, "Effective online teaching and learning practices for undergraduate health sciences students: An integrative review," Int. J. Africa Nurs. Sci., vol. 9, no. August, pp. 73-80, 2018.

[31] S. Ray and S. Srivastava, "Virtualization of science education: a lesson from the COVID-19 pandemic," $J$. Proteins Proteomics, vol. 11, no. 2, pp. 77-80, 2020. 
[32] M. Wildan Zulfikar, H. U. B. A. Umri, A. I. Bin Hashim, and A. R. A. Dahlan, "A business case for digital transformation of a Malaysian-based University," Proc. Int. Conf. Inf. Commun. Technol. Muslim World 2018, ICT4M 2018, no. 2016, pp. 106-109, 2018.

[33] M. H. Thowfeek and M. N. A. Salam, "Students' Assessment on the Usability of E-leaming Websites," Procedia - Soc. Behav. Sci., vol. 141, pp. 916-922, 2014.

[34] J. M. Locketz, "Pepperdine Digital Commons Exploring motivations and informal learning of school administrators adopting Google Apps for Education," 2019.

[35] R. K. Mahajan, "E-learning and pedagogical challenges: A study in student's response," ICDLE 2010 2010 4th Int. Conf. Distance Learn. Educ. Proc., pp. 159$162,2010$.

[36] R. Martínez-Jiménez and M. C. Ruiz-Jiménez, "Improving students' satisfaction and learning performance using flipped classroom," Int. J. Manag. Educ., vol. 18, no. 3, 2020.

[37] R. S. Jansen, A. van Leeuwen, J. Janssen, R. Conijn, and L. Kester, "Supporting learners' self-regulated learning in Massive Open Online Courses," Comput. Educ., vol. 146, no. November 2019, 2020.

[38] J. Giddens, K. Curry-lourenco, E. Miles, and E. Reeder, "Enhancing learning in an online doctoral course through a virtual community platform," J. Prof. Nurs., no. May, pp. 0-1, 2020.

[39] J. A. A. Abe, "Big five, linguistic styles, and successful online learning," Internet High. Educ., vol. 45, no. January, p. 100724, 2020.

[40] F. Martin, T. Sun, and C. Westine, "A Systematic Review of Research on Online Teaching and Learning from 2009 to 2018," Comput. Educ., vol. 159, no. April, p. $104009,2020$.

[41] D. L. Thomson, "Beyond the Classroom Walls: Teachers' and Students' Perspectives on How Online Learning Can Meet the Needs of Gifted Students," vol. 21, no. 4, pp. 662-712, 2010.

[42] H. Ku, H. Wei, and C. Akarasriworn, "Computers in Human Behavior Collaboration factors, teamwork satisfaction, and student attitudes toward online collaborative learning," Comput. Human Behav., vol. 29, no. 3, pp. 922-929, 2013.

[43] H. O. C. Wu, R. Wing, and P. Luk, "Interpreting TFIDF Term Weights as Making Relevance Decisions," vol. 26, no. 3, pp. 1-37, 2008.

[44] N. Kapasia et al., "Impact of lockdown on learning status of undergraduate and postgraduate students during COVID-19 pandemic in West Bengal, India," Child. Youth Serv. Rev., vol. 116, no. June, p. 105194, 2020.

[45] N. Iivari, S. Sharma, and L. Ventä-Olkkonen, "Digital transformation of everyday life - How COVID-19 pandemic transformed the basic education of the young generation and why information management research should care?," Int. J. Inf. Manage., no. June, p. 102183, 2020 . 